\title{
Biological function of Lemur tyrosine kinase 2 (LMTK2): implications in neurodegeneration
}

\author{
János Bencze ${ }^{1 \dagger}$, Gábor Miklós Mórotz ${ }^{2 \dagger}$, Woosung Seo ${ }^{1}$, Viktor Bencs ${ }^{1}$, János Kálmán ${ }^{3}$, \\ Christopher Charles John Miller ${ }^{2}$ and Tibor Hortobágyi ${ }^{1,4,5,6^{*}}$
}

\begin{abstract}
Neurodegenerative disorders are frequent, incurable diseases characterised by abnormal protein accumulation and progressive neuronal loss. Despite their growing prevalence, the underlying pathomechanism remains unclear. Lemur tyrosine kinase 2 (LMTK2) is a member of a transmembrane serine/threonine-protein kinase family. Although it was described more than a decade ago, our knowledge on LMTK2's biological functions is still insufficient. Recent evidence has suggested that LMTK2 is implicated in neurodegeneration. After reviewing the literature, we identified three LMTK2-mediated mechanisms which may contribute to neurodegenerative processes: disrupted axonal transport, tau hyperphosphorylation and enhanced apoptosis. Moreover, LMTK2 gene expression is decreased in an Alzheimer's disease mouse model. According to these features, LMTK2 might be a promising therapeutic target in near future. However, further investigations are required to clarify the exact biological functions of this unique protein.
\end{abstract}

Keywords: Alzheimer's disease, Axonal transport, LMTK2, Neurodegeneration, Tau

\section{Introduction}

Neurodegeneration is characterised by irreversible structural and functional damage of neurons leading to extensive cell death in numerous central nervous system disorders. According to the affected central nervous system regions, a wide range of clinical symptoms (e.g. dementia, movement disorder, etc.) can be observed. In definition, dementia is an acquired, progressive cognitive decline severe enough to make difficulties in daily-life [1]. Alzheimer's disease is the most frequent neurodegenerative dementia with a prevalence of 26.6 million [2]. There are several and relatively common neurodegenerative disorders (e.g. amyotrophic lateral sclerosis) where the neuronal damage affects other region of the central nervous system (i.e. motor neurons) although some forms of motor neuron diseases are also accompanied by cognitive impairments and dementia [3, 4]. Considering the fact that clinical symptoms usually appear

\footnotetext{
* Correspondence: tibor.hortobagyi@kcl.ac.uk

tEqual contributors

${ }^{1}$ Division of Neuropathology, Institute of Pathology, Faculty of Medicine, University of Debrecen, Nagyerdei krt. 98., Debrecen H-4032, Hungary

${ }^{4}$ MTA-DE Cerebrovascular and Neurodegenerative Research Group,

Debrecen, Hungary

Full list of author information is available at the end of the article
}

in elderly, except in uncommon familial forms, prevalence will undoubtedly increase in the next few decades. Prince et al. have predicted that the number of patients with dementia will double every 20 years reaching 115.4 million globally by 2050 [5]. This tendency in our aging society may raise dementia to the most challenging public health issue for the medical and social care system in the future. Despite their significance, neurodegenerative diseases are still incurable. The available therapies are limited to mitigation and mere delay of clinical symptoms. Therefore, intensive study of the field is essential to reveal the underlying pathomechanism and to identify new therapeutic targets for drug development. There is emerging evidence that alterations in the level of synaptic proteins and in their regulation are highly involved in the molecular pathogenesis [6-9], and clinical symptoms [10-12] of neurodegenerative disorders.

LMTK2, a brain enriched neuronal kinase has recently become of interest in neurodegenerative disease research since it regulates a number of fundamental cellular pathways linked to neurodegeneration. These include links to cyclin-dependent kinase 5 (CDK5)/p35, glycogen synthase kinase-3 $\beta$ (GSK3 $\beta)$, protein phosphatase-1 (PP1) 
and also the axonal transport machinery [13-16]. Therefore, changes in LMTK2 expression and activity may disrupt synaptic regulatory processes and axoplasmic flow to synapses leading to synaptic dysfunction, and neurodegeneration. Although our current knowledge on the biological functions of LMTK2 is limited compared to many other kinases, we aimed to provide a brief review of the literature and to delineate LMTK2's potential role in neurodegenerative pathology.

\section{Characteristics of LMTK2}

LMTK2 was originally described by three groups independently using yeast two-hybrid screens and database search $[14,16,17]$. The gene of LMTK2 has been mapped on human chromosome $7 \mathrm{q} 21.3$ and encodes a protein with molecular weight of $250 \mathrm{kDa}$. Due to parallel discoveries, LMTK2 is also known as kinase/phosphatase/inhibitor-2, CDK5/p35-regulated kinase, brainenriched kinase, apoptosis-associated tyrosine kinase-2 and KIAA1079 [14, 16-19]. LMTK2 is a member of the structurally unique membrane anchored lemur kinase protein family along with LMTK1A, LMTK1B and LMTK3 $[18,19]$. At first sight, LMTK2 appears to be a dual specific tyrosine-serine/threonine kinase based on the similarity of its kinase domain sequence to other tyrosine kinases. However, it has been demonstrated by independent studies that LMTK2 is a serine/threonine-specific kinase and do not target tyrosine residues $[14,17,20]$. Therefore, the name 'lemur tyrosine kinase' does not accurately reflect the kinase property of this protein. We suggest 'lemur tail kinase' as new name instead of the misleading and confusing 'lemur tyrosine kinase'. In this way, the acronym LMTK can be kept ensuring that the gene/protein naming remains consistent in the literature.

LMTK2's kinase activity was investigated by in vitro kinase assays and peptide microarray. In these experiments, recombinant and highly purified LMTK2 protein was used (i.e. no other kinase was present in the reaction) which exhibited autophosphorylation and also phosphorylated target proteins suggesting that LMTK2 is a constitutively active kinase $[14,20]$ LMTK2 is anchored into membranes by its tandem amino-terminal transmembrane domains in a way that both its aminoand carboxyl-termini face towards the cytoplasm [21]. The transmembrane domains are followed by an aminoterminal kinase domain and a long carboxyl-terminal 'tail'. This long 'tail' inspired the recently used name after the long-tailed Madagascan lemurs. LMTK2 is predominantly but not exclusively expressed in the brain and highly enriched in the hippocampus and cerebral cortex [16-19]. In neuronal cells, it is located in the cell body, along neurites and in growth cones [16-18]. Intracellularly, a proportion of LMTK2 is present in the Golgi apparatus and early endosomes [16, 22, 23]. LMTK2 starts to be highly expressed in the first two-three postnatal weeks [16-18] suggesting its role in postnatal neuronal development. In support of this notion, LMTK2 is reported to undergo rapid, protein kinase $\mathrm{C}$ (PKC)-dependent phosphorylation in PC12 cells following neuronal growth factor (NGF) stimulation however, if PKC directly phosphorylates LMTK2 is not known $[17,20]$. NGF signalling reduces LMTK2 activity which in turn enhances neurite outgrowth indicating that LMTK2 is a negative regulator of neuronal differentiation $[17,20]$. Another regulator of LMTK2 kinase activity is CDK5/p35 and the details of this regulatory mechanism are discussed in the next section below. Interestingly, the carboxyl-terminal tail of LMTK2 contains seven proline-(any residue-any residue)-proline (PxxP) motifs [17]. Proteins with PxxP motif can directly bind to proteins with Src homology 3 (SH3) domain [24, 25]. Numerous kinases contain SH3 domains or interact with target proteins via $\mathrm{SH} 3$ domain containing scaffolding proteins $[26,27]$. Therefore, LMTK2 might be regulated by kinases with SH3 domains or alternatively, LMTK2 can phosphorylate downstream targets by recruiting them by its PxxP motifs. Although this is an attractive theory no SH3 domain containing LMTK2 binding partner has been identified yet.

To date, one LMTK2 animal model has been published. LMTK2 knockout mice have been found to be viable but male mice are infertile due to azoospermia [28]. This alteration derives from the defected maturation of germ cells, suggesting that LMTK2 is also essential to physiological spermatogenesis. However, the effects of LMTK2 loss on the nervous system in these animals has not been properly studied and reported. In order to dissect neuronal function of LMTK2, further LMTK2 animal models need to be developed and investigated.

\section{LMTK2 interacting partners}

Although a fully detailed interacting network of LMTK2 remains to be elucidated there are several known protein-binding partners and signalling pathways which suggest essential role of LMTK2 in key cellular processes. LMTK2 interacting partners include CDK5/p35, the catalytic subunit of protein phosphatase 1 (PP1C) and myosin VI. Details of their interaction and potential cellular functions are discussed below.

\section{CDK5/p35}

CDKs are proline-directed serine/threonine proteinkinases involved in cell cycle and transcription regulation, neuronal morphogenesis, and neuronal differentiation [29]. LMTK2 interacts with CDK5 via binding to p35, the activator subunit of CDK5 $[15,16]$. This interaction is mediated by a sequence (amino acid 391-632) 
closely located to the kinase domain of LMTK2 however, where LMTK2 binds to p35 and how this interaction is regulated is not known [16]. CDK5 is a unique member of the CDK family. Unlike other CDKs, CDK5 does not require activating phosphorylation by cyclins instead it needs binding to activator proteins or their cleaved counterparts $\mathrm{p} 35 / \mathrm{p} 25$, or p39/p29 [30, 31]. CDK5 has vital role in neuronal maturation, migration, synaptic plasticity and memory formation as well as in synaptic vesicle exocytosis by phosphorylating several downstream targets [29, 31]. CDK5/p35 not only binds to LMTK2 but also phosphorylates it on serine-1418 [15, 16]. This phosphorylation induces increased LMTK2 kinase activity and simultaneously stimulates its ability to phosphorylate downstream targets such as PP1C [15]. Thus, LMTK2 together with CDK5/p35 can regulate key neuronal processes which are vital for proper neuronal functioning. CDK5 is functionally inactive in non-neuronal tissues because CDK5 activator p35 expression is restricted to neurons [15, 32-34]. Nevertheless, a small amount of phospho-LMTK2 serine-1418 was still detectable in nonneuronal cells suggesting that other kinases can also activate LMTK2 by phosphorylating LMTK2 serine-1418 in non-neuronal tissues [15]. Interestingly, both CDK5 and mitogen-activated protein kinase (MAPK) are prolinedirected serine/threonine protein-kinases with a very similar consensus sequences which are (any residue)-serine/ threonine-proline-(any residue)-lysin/histidine/arginine for CDK5, and proline-(any residue)-serine/threonine-proline for MAPK $[35,36]$. This similarity that both CDK5 and MAPK require a proline immediately downstream of the targeted serine/threonine residue raises the possibility that MAPK might also target the same residues in LMTK2 as CDK5. Thus, LMTK2 kinase activity might not only been regulated by CDK5/p35 but also by MAPK. Indeed, experimental data show that treating PC12 cells with NGF or PKC activator increases MAPK/CDK specific phosphorylation of LMTK2 however, if this increased phosphorylation was induced directly by MAPK or CDK5 is not known [17]. To sum up, LMTK2 can phosphorylate and regulate downstream targets, and play important role in both neuronal and non-neuronal processes.

\section{PP1C}

PP1 is a protein serine/threonine phosphatase which is involved in myriad fundamental cellular functions. Interacting with distinct regulatory subunits, PP1C controls cell cycle, apoptosis, glycogen homeostasis, RNA splicing, protein synthesis, muscle activity and neuronal processes $[37,38]$. PP1C binds to proteins with an arginine-valine(any residue)-phenylalanine motif, also known as $\mathrm{RVxF}$ motif [39, 40]. LMTK2 contains a valine-threoninephenylalanine (VTF) motif close to its carboxyl-terminus and binds to PP1C through this motif [13-15]. Upon binding to PP1C, LMTK2 phosphorylates it on threonine-320 which attenuates the phosphatase activity of PP1C [13-15]. This PP1C inhibitory activity of LMTK2 is facilitated by CDK5/p35-dependent phosphorylation of LTMK2 on serine-1418, thus CDK5/p35 and PP1C together with LMTK2 function in one common signalling pathway $[13,15]$. Interestingly, LMTK2 also binds to inhibitor-2, one of the regulatory subunits of PP1C which restricts PP1C activity when they interact $[14,41]$. Thus, LMTK2 regulates PP1C activity and in this way downstream cellular processes by two independent mechanisms phosphorylating it on threonine-320, and complex it with inhibitor-2.

\section{Myosin VI}

Myosin VI is an actin-based molecular motor protein involved in retrograde transport of endo- and exocytotic membranes. It is known that some binding partners of myosin VI are involved in intracellular targeting and recruitment of myosin VI [42-45]. Two research groups simultaneously identified LMTK2 as a myosin VI binding partner. LMTK2 directly binds to a tryptophan-tryptophantyrosine (WWY) motif in the carboxyl-terminal tail of myosin VI $[22,46]$. The WWY motif is the same site where other endocytic adaptor proteins bind to myosin VI however, how cargoes are selected and their binding to myosin VI is regulated is not known [42, 46, 47]. LMTK2 binds to the WWY motif of myosin VI through a region close to its kinase domain (amino acid 567-773) which overlaps with the p35 binding region (amino acid 391-632) [16, 22]. This overlap between the residues where myosin VI and p35 associate to LMTK2 raise the possibility of competition between myosin VI and p35 for LMTK2 binding although, to date, there is no confirming experimental data. LMTK2 and myosin VI co-localise in endocytic and recycling endocytic vesicle compartments. Through binding to myosin VI, LMTK2 is essential for the endocytic transport of transferrin receptor, a cargo of myosin VI [22, 23]. Interestingly, cystic fibrosis transmembrane conductance regulator (CFTR), a chloride ion selective ion channel which mutation causes cystic fibrosis, binds not only to myosin VI but also directly interacts with LMTK2 [20, 48-50]. In addition, CFTR is also a substrate of LMTK2. Phosphorylation of CFTR on serine-737 by LMTK2 enhances CFTR endocytosis and thus LMTK2 regulates CFTR availability on the cell surface $[20,48]$. These findings indicate that LMTK2 has significant role in the orchestration of endocytic/recycling machinery together with myosin VI. Yet, the exact regulation of this mechanism remains to be elucidated.

\section{Implications in neurodegeneration}

LMTK2 is involved in neuronal outgrowth and development, axonal transport, intracellular vesicle trafficking, and apoptosis $[13,22,23,48,51]$. Yet, the precise way 
how LMTK2 orchestrates these processes remains undiscovered. The determinant alterations in neurodegeneration are disrupted axonal transport, pathological accumulation/aggregation of disease-specific proteins and dysregulated apoptosis which together lead to neuronal loss [52,53]. Taking into account of biological functions of LMTK2, there is a plausible link between LMTK2 and neurodegenerative processes (Fig. 1).

LMTK2 is enriched in the brain suggesting its crucial role in the central nervous system [16-19]. A recent genome-wide gene-expression study compared five amyloid and tau transgenic mice lines, and created a database [54]. Progressively decreasing LMTK2 expression was found in the cortex and hippocampus predominantly in the tau mouse model (Tau P301L) during the disease development, and this reduction correlates with pathological changes. In contrast, in the cerebellum, increased LMTK2 expression was detected and the animals did not show any cerebellar Alzheimer's disease pathology. As it is detailed above, CDK5/p35 phosphorylates LMTK2 to activate it [15]. In neurodegeneration linked cellular stress conditions, such as $\beta$-amyloid overproduction or oxidative stress, calcium-dependent cysteine protease calpain is activated, and proteolytically cleaves p35 into p 25 and p10 [55-58]. Owing to its longer half-life, p25 prolongs the active state of CDK5 resulting in increased phosphorylation of downstream targets $[56,59,60]$. However, if CDK5/p25 can phosphorylate LMTK2 in the same way as CDK5/p35 is not known. Although the number of experimental studies is

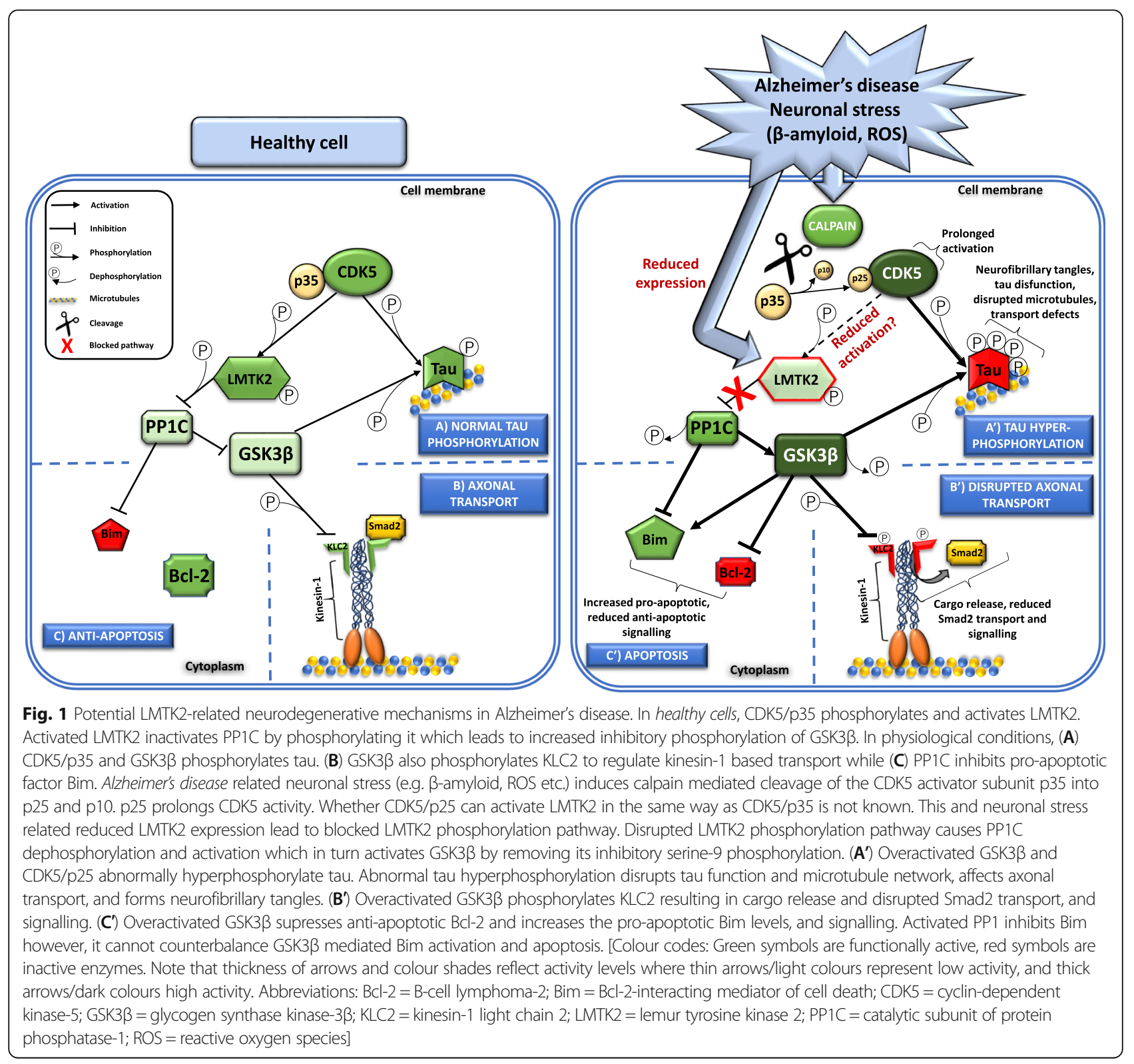


certainly limited, based on the known biological functions and interacting partners, we attempt to provide a brief explanation how the previously reported reduced LMTK2 levels in Alzheimer's disease animal model, and potentially disrupted phosphorylation cascade can contribute the disease pathology.

\section{Disrupted axonal transport}

Physiological axonal transport is fundamental for maintaining the complex neuronal homeostasis. Neurons are polarised cells with majority of their proteins synthetized in the soma and require therefore well-organized intracellular transport to reach their targets. There are four vital actors in this play: microtubule tracks, molecular motor proteins, cargoes and energy in the form of ATP. Any disruption to this precise machinery perturbs axonal transport and causes aberrant accumulation of proteins, and organelles in different neurodegenerative pathologies in dementias, movement disorders and motor neuron diseases, for review see [52].

Kinesin-1 is a major molecular motor protein mediating axonal transport of several key cargoes such as mitochondria, amyloid precursor protein and synaptic vesicle precursors towards synapses [61-64]. Most functional kinesin-1 is a heterotetramer composed of two kinesin-1 heavy chains and two kinesin-1 light chains (KLCs). Kinesin-1 heavy chains move along microtubules while KLCs are mainly involved in cargo binding [62]. Phosphorylation of KLCs is an important cargo binding and releasing regulatory mechanism $[61,65,66]$. GSK3 $\beta$ can directly phosphorylate KLC2 to induce cargo release and supress kinesin-1 mediated transport [13, 65]. Involvement of CDK5 in GSK3 $\beta$-dependent regulation of axonal transport was first described by Morfini et al. [66]. They have reported that CDK5 indirectly regulates GSK3 $\beta$ activity via PP1C. However, the nature of interaction (i.e. direct or indirect) between CDK5/p35 and PP1C was unclear [66]. Manser and co-workers have recently revealed that LMTK2 is the missing link between CDK5/ $\mathrm{p} 35, \mathrm{PP} 1 \mathrm{C}$ and GSK3 $\beta$ which brings these proteins together in one phosphorylation pathway to regulate kinesin-1 based axonal transport [13, 15]. In this novel signalling pathway, CDK5/p35 activates LMTK2 by phosphorylating it at serine-1418. Phosphorylated LMTK2 in turn reduces PP1C activity by phosphorylating it at threonine-320. Finally, phosphorylation of PP1C threonine-320 leads to increased inhibitory phosphorylation of GSK3 $\beta$ at serine- $9[13,15]$. Inhibited GSK3 $\beta$ is not able to phosphorylate KLC2 which promotes KLC2 binding to cargos, such as mothers against decapentaplegic homolog 2 (Smad2). Thus, LMTK2 is a negative regulator of KLC2 phosphorylation and LMTK2 activity promotes kinesin-1 based transport of Smad2 [13, 67]. Smad2 is a transcription factor which shuttles between the cytoplasm and nucleus, and is a crucial player in transforming growth factor- $\beta$ (TGF $\beta$ ) signalling pathway [68]. TGF $\beta$ induces Smad2 translocation into the nucleus where it regulates the expression of TGF $\beta$ responsive genes [69]. siRNA knockdown of LMTK2 disrupts Smad2 binding to KLC2 and importantly, it also inhibits TGF $\beta$-induced nuclear signalling of Smad2 probably due to affected Smad2 transport [13]. Reduced LTMK2 gene-expression has been detected in an Alzheimer's disease tau mouse model [54]. Additionally, altered TGF $\beta /$ Smad2 signalling has been observed in common neurodegenerative diseases, including Alzheimer's disease $[70,71]$ suggesting that LMTK2 is not only involved in the regulation of kinesin-1 based transport but also can contribute the pathomechanism of neurodegenerative diseases by affecting axonal transport.

\section{Tau hyperphosphorylation}

Neurofibrillary tangles are hallmark intraneuronal pathological features of Alzheimer's disease. Neurofibrillary tangles consist of misfolded and abnormally hyperphosphorylated tau, a microtubule-associated protein $[72,73]$. CDK5 and GSK3 $\beta$ are major tau kinases which are involved in tau hyperphosphorylation in vivo [74-77]. Although both CDK5 and GSK3 $\beta$ are sufficient to hyperphosphorylate tau, negative correlation has been revealed between their activities. It has been shown that increased CDK5 activity inhibits GSK3 $\beta$ by increasing its inhibitory phosphorylation at serine-9 $[13,15,66,78,79]$. Interestingly, CDK5 mediated GSK3 $\beta$ inhibition is age dependent. In young mice, GSK3 $\beta$ activity is reduced compared to aged mice where GSK3 $\beta$ activity is increased causing tau hyperphosphorylation [79, 80]. The exact mechanism of age dependently enhanced GSK3 $\beta$ activity and tau hyperphosphorylation is not known. One possible explanation is that the molecular breaking mechanism which inhibits GSK3 $\beta$ activity is defective. Progressively decreasing LMTK2 levels seen in an Alzheimer's disease mouse model [54] could potentially lead to aberrant overactivation of GSK3 $\beta$ in aged mice. It is important to note that decreased LMTK2 levels and/or kinase activity leads to increased PP1C activity $[13,15]$. It is also known that hyperphosphorylated tau filaments are able to activate PP1 [81-83]. PP1 can dephosphorylate tau on some residues which are abnormally hyperphosphorylated in Alzheimer's disease [84, 85]. In fact, despite increased PP1 activity, tau remains hyperphosphorylated in Alzheimer's disease suggesting that elevated tau phosphatase activity of PP1C cannot counterbalance increased GSK3 $\beta$ activity. The above hypothesis explains some aspects of tau hyperphosphorylation however, it needs further investigation. 
Table 1 Gene expression studies of LMTK2 in neurodegeneration

\begin{tabular}{|c|c|c|c|c|c|c|}
\hline Disease & Research model & Disease sample & Control sample & $\begin{array}{l}\text { LMTK2 gene } \\
\text { expression in disease } \\
\text { sample }\end{array}$ & $\begin{array}{l}\text { Statistical } \\
\text { significance }\end{array}$ & $\overline{\text { Reference }}$ \\
\hline $\begin{array}{l}\text { Alzheimer's } \\
\text { disease }\end{array}$ & Mouse tissue & $\begin{array}{l}\text { Tau P301L cortex and } \\
\text { hippocampus }\end{array}$ & $\begin{array}{l}\text { Wild-type cortex } \\
\text { and hippocampus }\end{array}$ & Decreased & Not known & [54] \\
\hline $\begin{array}{l}\text { Parkinson's } \\
\text { disease }\end{array}$ & Human tissue & Substantia nigra & $\begin{array}{l}\text { Substantia nigra } \\
\text { from controls }\end{array}$ & Decreased & Not known & [107] \\
\hline $\begin{array}{l}\text { Amyotrophic } \\
\text { lateral sclerosis }\end{array}$ & $\begin{array}{l}\text { Human embryonic stem } \\
\text { cell-derived motor neuron }\end{array}$ & $\begin{array}{l}\text { Neurons exposed to mutant SOD1 } \\
\text { astrocyte conditioned medium }\end{array}$ & $\begin{array}{l}\text { Non-treated } \\
\text { neurons }\end{array}$ & Decreased & Not known & [108] \\
\hline $\begin{array}{l}\text { Huntington's } \\
\text { disease }\end{array}$ & Mouse tissue & DE5 (D9-N171-98Q) striatum & Wild-type striatum & Decreased & $\begin{array}{l}\text { Yes }(p= \\
0,025)\end{array}$ & [109] \\
\hline
\end{tabular}

\section{Apoptosis}

A recent siRNA-based high-throughput screen has identified LMTK2 as a potential regulator of apoptosis [51]. siRNA mediated LMTK2 knockdown decreases antiapoptotic B-cell lymphoma-2 (Bcl-2) and B-cell lymphoma-extra-large (Bcl-xL), and increases proapoptotic Bcl-2-interacting mediator of cell death (Bim) protein levels [51]. These LMTK2-associated alterations made cells more sensitive to toxic effects of apoptosis inducing ligands and other cytotoxic compounds. The effect of LMTK2 silencing on Bim levels is mediated by increased PP1C and GSK3 $\beta$ activity [51]. Bim levels are also decreased in the brain of Alzheimer's disease patients and $\mathrm{Bcl}-2$ is protective against Alzheimer's disease-related insults [86, 87]. LMTK2 silencing was also accompanied by decreased Akt and extracellular signal-regulated kinase-1/ 2 (ERK1/2) activity [51, 88-91]. These changes can also contribute to apoptosis but the exact mechanism how LMTK2 can modulate Akt and ERK1/2 activity is not known. In essence, these results suggest that decreased LMTK2 levels can sensitise cells to cytotoxicity via affecting apoptotic and survival pathways, and it is consistent with the hypothesis that reduced LMTK2 levels may contribute to cell death in neurodegeneration.

According to our current knowledge, the majority of neurons are terminally differentiated cells [92]. However, certain noxious stimuli (e.g. oxidative stress, $\beta$-amyloid peptide, tau hyperphosphorylation) can induce aberrant cell cycle reactivation [20, 29, 93-95]. Since neurons lost their proliferative capacity, the abnormal cell cycle reentry is interrupted by different regulatory mechanisms leading to apoptosis, for review see $[95,96]$. Therefore, noxious stimuli which induce uncontrolled cell proliferation in other tissues could cause extensive cell death in neuronal tissue. In neurons, aberrant cell cycle reactivation upregulates cyclin D and cyclin E expression, and increases the activity of $G_{1}$ and $G_{2}$ phase CDKs [97-102]. Increased $\mathrm{CDK}$ activity results in retinoblastoma protein phosphorylation and concomitant E2F release in neurons [99, 102, 103]. E2F promotes the expression of proapoptotic genes and transactivates downstream cell cycle genes triggering the progression of the lethal apoptotic cycle [104]. Considering LMTK2 as tumour suppressor/ pro-apoptotic protein, it is possible that E2F reduces LMTK2 levels by transcriptional silencing. Supporting this theory, several studies have reported decreased LMTK2 expression in both neurodegeneration and cancer [54, 105-109]. Nevertheless, the potential link between E2F and the LMTK2 gene has yet to be explored.

\section{Conclusion and prospects}

Prevalence of neurodegenerative diseases are exponentially increasing in our aging society. Considering that these frequent pathologies mostly affect the elderly, it is critical to provide an effective solution to this urgent issue. Although our knowledge is still insufficient, the latest studies point toward to the same direction: LMTK2 is involved in neurodegeneration (Table 1).

Despite the limited amount of studies in the field, LMTK2 seems to be mis- and downregulated in Alzheimer's, and other neurodegenerative diseases. Therefore, manipulation of the protein level could be a promising novel therapeutic target. A recent study has identified a 2-O-Tetradecanoylphorbol-13-acetate (TPA) responsive element in LMTK2 gene [110]. TPA is a synthetic PKC activator with ability to increase LMTK2 expression. The mechanism requires activator protein-1 transcription factor complex binding to LMTK2 promoter region in which the complex is trans-activated by protein kinase $C$ [110]. These results are probably valuable but certainly not sufficient for drug development. Thus, further comprehensive investigations are essential to reveal and to understand the function of LMTK2 in neurodegenerative processes.

\section{Abbreviations}

BCl-2: B-cell lymphoma-2; Bcl-xL: B-cell lymphoma-extra-large; Bim: BCl-2interacting mediator of cell death; CDK5: Cyclin-dependent kinase 5; CFTR: Cystic fibrosis transmembrane conductance regulator; ERK1/

2: Extracellular signal-regulated kinase-1/2; GSK3 3 : Glycogen synthase kinase3ß; KLC: Kinesin-1 light chain; LMTK2: Lemur tyrosine kinase 2;

MAPK: Mitogen-activated protein kinase; NGF: Neuronal growth factor; PKC: Protein kinase C; PP1: Protein phosphatase-1; PP1C: catalytic subunit of PP1; PxxP: proline-(any residue-any residue)-proline; SH3: Src homology 3; 
Smad2: Mothers against decapentaplegic homolog 2; TGF $\beta$ : Transforming growth factor- $\beta$; TPA: 2-O-Tetradecanoylphorbol-13-acetate; VTF: Valinethreonine-phenylalanine; WWY: Tryptophan-tryptophan-tyrosine

\section{Acknowledgements}

Not applicable.

\section{Funding}

Supported by the ÚNKP-17-3 New National Excellence Program of the Ministry of Human Capacities and EFOP-3.6.3-VEKOP-16-2017-00009 (JB); GINOP-2.3.2-15-2016-00043 and Hungarian Brain Research Program (20171.2.1-NKP-2017-00002) (TH); KTIA_NAP_13-1-2013-0001 (JK); BBSRC (BB/ L019299/1) (CCJM) and ARUK (CCJM and GMM). GMM's work was supported by the Alzheimer's Research UK King's College London Network Centre

\section{Availability of data and materials}

Not applicable.

\section{Authors' contributions}

Conception and design of the study by JB, TH and GMM. Primary draft by JB aided by VB and WS. Revisions by GMM and TH, amended by JK and CCJM. All authors have read and approved the final version.

\section{Ethics approval and consent to participate}

Not applicable.

\section{Consent for publication}

Not applicable.

\section{Competing interests}

The authors declare that they have no competing interests.

\section{Publisher's Note}

Springer Nature remains neutral with regard to jurisdictional claims in published maps and institutional affiliations.

\section{Author details}

${ }^{1}$ Division of Neuropathology, Institute of Pathology, Faculty of Medicine, University of Debrecen, Nagyerdei krt. 98., Debrecen H-4032, Hungary. ${ }^{2}$ Department of Basic and Clinical Neuroscience, Institute of Psychiatry Psychology and Neuroscience, King's College London, London, UK ${ }^{3}$ Department of Psychiatry, Faculty of Medicine, University of Szeged, Szeged, Hungary. ${ }^{4}$ MTA-DE Cerebrovascular and Neurodegenerative Research Group, Debrecen, Hungary. ${ }^{5}$ Department of Pathology, Faculty of Medicine, University of Szeged, Szeged, Hungary. 'Department of Old Age Psychiatry, Institute of Psychiatry Psychology and Neuroscience, King's College London, London, UK.

Received: 1 February 2018 Accepted: 26 March 2018

\section{Published online: 10 April 2018}

\section{References}

1. American Psychiatric Association. Diagnostic and Statistical Manual of Mental Disorders. Fourth ed. Arlington: Text Revision (DSM-IV-TR); 2000. https://doi.org/10.1176/appi.books.9780890423349.

2. Brookmeyer R, Johnson E, Ziegler-Graham K, Arrighi HM. Forecasting the global burden of Alzheimer's disease. Alzheimers Dement. 2007:3:186-91. https://doi.org/10.1016/j.jalz.2007.04.381.

3. Hardiman O, Al-Chalabi A, Chio A, Corr EM, Logroscino G, Robberecht W, et al. Amyotrophic lateral sclerosis. Nat Rev Dis Primers. 2017;3:17071. https://doi.org/10.1038/nrdp.2017.71.

4. Strong MJ, Abrahams S, Goldstein LH, Woolley S, Mclaughlin P, Snowden J, et al. Amyotrophic lateral sclerosis - frontotemporal spectrum disorder (ALSFTSD): revised diagnostic criteria. Amyotroph Lateral Scler Front Degener. 2017:18:153-74. https://doi.org/10.1080/21678421.2016.1267768.

5. Prince M, Bryce R, Albanese E, Wimo A, Ribeiro W, Ferri CP. The global prevalence of dementia: a systematic review and metaanalysis. Alzheimer's and Dementia. 2013;9:63-75. https://doi.org/10.1016/j.jalz.2012.11.007.

6. Tiwari SS, D'Orange M, Troakes C, Shurovi BN, Engmann O, Noble W, et al. Evidence that the presynaptic vesicle protein CSPalpha is a key player in synaptic degeneration and protection in Alzheimer's disease. Mol Brain. 2015:8:6. https://doi.org/10.1186/s13041-015-0096-z.

7. Vallortigara J, Rangarajan S, Whitfield D, Alghamdi A, Howlett D, Hortobágyi $T$, et al. Dynamin1 concentration in the prefrontal cortex is associated with cognitive impairment in Lewy body dementia. F1000Research. 2014;3:108. https://doi.org/10.12688/f1000research.3786.1.

8. Whitfield DR, Vallortigara J, Alghamdi A, Howlett D, Hortobágyi T, Johnson M, et al. Assessment of ZnT3 and PSD95 protein levels in Lewy body dementias and Alzheimer's disease: association with cognitive impairment. Neurobiol Aging. 2014;35:2836-44. https://doi.org/10.1016/j.neurobiolaging.2014.06.015.

9. Bereczki E, Francis PT, Howlett D, Pereira JB, Höglund K, Bogstedt A, et al. Synaptic proteins predict cognitive decline in Alzheimer's disease and Lewy body dementia. Alzheimers Dement. 2016;12:1149-58. https://doi.org/10. 1016/j.jalz.2016.04.005

10. Bencze J, Simon V, Bereczki E, Majer R, Varkoly G, Murnyák B, et al. Clinical and neuropathological characteristics of dementia with Lewy bodies [A Lewy-testes demencia klinikai és neuropatológiai jellemzői]. Orv Hetil. 2017; 158:643-52. [Hungarian]. https://doi.org/10.1556/650.2017.30735.

11. Whitfield DR, Vallortigara J, Alghamdi A, Hortobágyi T, Ballard C, Thomas AJ, et al. Depression and synaptic zinc regulation in Alzheimer disease, dementia with lewy bodies, and Parkinson disease dementia. Am J Geriatr Psychiatry. 2015;23:141-8. https://doi.org/10.1016/j.jagp.2014.05.001.

12. Vallortigara J, Whitfield D, Quelch W, Alghamdi A, Howlett D, Hortobágyi T, et al. Decreased levels of VAMP2 and monomeric alpha-Synuclein correlate with duration of dementia. J Alzheimers Dis. 2015;50:101-10. https://doi.org/ 10.3233/JAD-150707.

13. Manser C, Guillot F, Vagnoni A, Davies J, Lau KF, McLoughlin DM, et al. Lemur tyrosine kinase-2 signalling regulates kinesin-1 light chain-2 phosphorylation and binding of Smad2 cargo. Oncogene. 2012;31:2773-82. https://doi.org/10.1038/onc.2011.437.

14. Wang $H$, Brautigan DL. A novel transmembrane Ser/Thr kinase complexes with protein phosphatase-1 and inhibitor-2. J Biol Chem. 2002;277:4960512. https://doi.org/10.1074/jbc.M209335200.

15. Manser C, Vagnoni A, Guillot F, Davies J, Miller CCJ. Cdk5/p35 phosphorylates lemur tyrosine kinase-2 to regulate protein phosphatase-1C phosphorylation and activity. J Neurochem. 2012;121:343-8. https://doi.org/ 10.1111/j.1471-4159.2012.07650.x

16. Kesavapany S, Lau K-F, Ackerley S, Banner SJ, Shemilt SJA, Cooper JD, et al. Identification of a novel, membrane-associated neuronal kinase, cyclindependent kinase 5/p35-regulated kinase. J Neurosci. 2003;23:4975-83.

17. Kawa S, Fujimoto J, Tezuka T, Nakazawa T, Yamamoto T. Involvement of BREK, a serine/threonine kinase enriched in brain, in NGF signalling. Genes Cells. 2004;9:219-32. https://doi.org/10.1111/j.1356-9597.2004.00714.x.

18. Tomomura M, Morita N, Yoshikawa F, Konishi A, Akiyama H, Furuichi T, et al. Structural and functional analysis of the apoptosis-associated tyrosine kinase (AATYK) family. Neuroscience. 2007;148:510-21. https://doi.org/10.1016/j. neuroscience.2007.05.048.

19. Kikuno R, Nagase T, Ishikawa Kl, Hirosawa M, Miyajima N, Tanaka A, et al. Prediction of the coding sequences of unidentified human genes. XIV. The complete sequences of 100 new cDNA clones from brain which code for large proteins in vitro. DNA Res. 1999;6:197-205. https://doi.org/10.1093/ dnares/6.3.197.

20. Wang $\mathrm{H}$, Brautigan DL. Peptide microarray analysis of substrate specificity of the transmembrane Ser/Thr kinase KPI-2 reveals reactivity with cystic fibrosis transmembrane conductance regulator and phosphorylase. Mol Cell Proteomics. 2006;5:2124-30. https://doi.org/10.1074/mcp.M600188-MCP200.

21. Nixon A, Jia Y, White C, Bradbury NA. Determination of the membrane topology of lemur tyrosine kinase 2 (LMTK2) by fluorescence protease protection. AJP Cell Physiol. 2013;304:C164-9. https://doi.org/10.1152/ajpcell.00288.2012.

22. Chibalina MV, Seaman MNJ, Miller CC, Kendrick-Jones J, Buss F. Myosin VI and its interacting protein LMTK2 regulate tubule formation and transport to the endocytic recycling compartment. J Cell Sci. 2007;120:4278-88. https://doi.org/10.1242/jcs.014217.

23. Inoue T, Kon T, Ohkura R, Yamakawa H, Ohara O, Yokota J, et al. BREK/LMTK2 is a myosin VI-binding protein involved in endosomal membrane trafficking. Genes Cells. 2008;13:483-95. https://doi.org/10.1111/j.1365-2443.2008.01184x.

24. Chen JK, Lane WS, Brauer AW, Tanaka A, Schreiber SL. Biased combinatorial libraries: novel ligands for the SH3 domain of phosphatidylinositol 3-kinase. J Am Chem Soc. 1993;115:12591-2. https://doi.org/10.1021/ja00079a051.

25. Ren R, Mayer BJ, Cicchetti $P$, Baltimore $D$. Identification of a ten-amino acid proline-rich SH3 binding site. Science. 1993;259:1157-61. 
26. Mayer BJ. The discovery of modular binding domains: building blocks of cell signalling. Nat Rev Mol Cell Biol. 2015;16:691-8. https:/doi.org/10.1038/nrm4068.

27. Kurochkina N, Guha U. SH3 domains: modules of protein-protein interactions. Biophys Rev. 2013;5:29-39. https://doi.org/10.1007/s12551012-0081-z.

28. Kawa S, Ito C, Toyama Y, Maekawa M, Tezuka T, Nakamura T, et al. Azoospermia in mice with targeted disruption of the Brek/Lmtk2 (brainenriched kinase/lemur tyrosine kinase 2) gene. Proc Natl Acad Sci U S A. 2006;103:19344-9. https://doi.org/10.1073/pnas.0603603103.

29. Monaco EA 3rd, Vallano ML. Role of protein kinases in neurodegenerative disease: cyclin-dependent kinases in Alzheimer's disease. Front Biosci. 2005; 10:143-59.

30. Shupp A, Casimiro MC, Pestell RG. Biological functions of CDK5 and potential CDK5 targeted clinical treatments. Oncotarget. 2017;8:17373-82. https://doi.org/10.18632/oncotarget.14538.

31. Su SC, Tsai L-H. Cyclin-dependent kinases in brain development and disease. Annu Rev Cell Dev Biol. 2011;27:465-91. https://doi.org/10.1146/ annurev-cellbio-092910-154023.

32. Tsai L-H, Delalle I, Caviness VS, Chae T, Harlow E. p35 is a neural-specific regulatory subunit of cyclin-dependent kinase 5. Nature. 1994;371:419-23. https://doi.org/10.1038/371419a0.

33. Guidato S, Tsai LH, Woodgett J, Miller CC. Differential cellular phosphorylation of neurofilament heavy side-arms by glycogen synthase kinase-3 and cyclin-dependent kinase-5. J Neurochem. 1996;66:1698-706. https://doi.org/10.1046/j.1471-4159.1996.66041698.x.

34. Li BS, Zhang L, Gu J, Amin ND, Pant HC. Integrin alpha(1) beta(1)-mediated activation of cyclin-dependent kinase 5 activity is involved in neurite outgrowth and human neurofilament protein $\mathrm{H}$ Lys-Ser-Pro tail domain phosphorylation. J Neurosci. 2000;20:6055-62. doi:20/16/6055

35. Sheridan DL, Kong Y, Parker SA, Dalby KN, Turk BE. Substrate discrimination among mitogen-activated protein kinases through distinct docking sequence motifs. J Biol Chem. 2008;283:19511-20. https://doi.org/10.1074/ jbc.M801074200.

36. Songyang Z, Lu KP, Kwon YT, Tsai LH, Filhol O, Cochet C, et al. A structural basis for substrate specificities of protein Ser/Thr kinases: primary sequence preference of casein kinases I and II, NIMA, phosphorylase kinase, calmodulin-dependent kinase II, CDK5, and Erk1. Mol Cell Biol. 1996;16: 6486-93. https://doi.org/10.1128/MCB.16.11.6486.

37. Cohen PTW. Protein phosphatase 1-targeted in many directions. J Cell Sci. 2002;115(Pt2):241-56.

38. Bollen M, Peti W, Ragusa MJ, Beullens M. The extended PP1 toolkit: designed to create specificity. Trends Biochem Sci. 2010;35:450-8. https:// doi.org/10.1016/j.tibs.2010.03.002.

39. Egloff M-P. Structural basis for the recognition of regulatory subunits by the catalytic subunit of protein phosphatase 1. EMBO J. 1997;16:1876-87. https://doi.org/10.1093/emboj/16.8.1876.

40. Hendrickx A, Beullens M, Ceulemans H, Den Abt T, Van Eynde A, Nicolaescu $E$, et al. Docking motif-guided mapping of the Interactome of protein Phosphatase-1. Chem Biol. 2009;16:365-71. https://doi.org/10.1016/j. chembiol.2009.02.012.

41. HUANG FL, GLINSMANN WH. Separation and characterization of two phosphorylase phosphatase inhibitors from rabbit skeletal muscle. Eur J Biochem. 1976;70:419-26. https://doi.org/10.1111/j.1432-1033.1976.tb11032.x

42. Spudich G, Chibalina MV, Au JSY, Arden SD, Buss F, Kendrick-Jones J. Myosin $\mathrm{VI}$ targeting to clathrin-coated structures and dimerization is mediated by binding to Disabled-2 and Ptdlns(4,5)P2. Nat Cell Biol. 2007;9:176-83. https://doi.org/10.1038/ncb1531.

43. Naccache SN, Hasson T, Horowitz A. Binding of internalized receptors to the PDZ domain of GIPC/synectin recruits myosin VI to endocytic vesicles. PNAS. 2006;103:12735-40. https://doi.org/10.1073/pnas.0605317103.

44. Bunn RC, Jensen MA, Reed BC. Protein interactions with the glucose transporter binding protein GLUT1CBP that provide a link between GLUT1 and the cytoskeleton. Mol Biol Cell. 1999;10:819-32. https://doi.org/10.1091/mbc.10.4.819.

45. Morris SM, Arden SD, Roberts RC, Kendrick-Jones J, Cooper JA, Luzio JP, et al. Myosin VI binds to and localises with Dab2, potentially linking receptormediated endocytosis and the actin cytoskeleton. Traffic. 2002;3:331-41. https://doi.org/10.1034/j.1600-0854.2002.30503.x

46. Arden SD, Tumbarello DA, Butt T, Kendrick-Jones J, Buss F. Loss of cargo binding in the human myosin VI deafness mutant (R1166X) leads to increased actin filament binding. Biochem J. 2016:473:3307-19. https://doi. org/10.1042/BCJ20160571.
47. Tumbarello DA, Waxse BJ, Arden SD, Bright NA, Kendrick-Jones J, Buss F. Autophagy receptors link myosin VI to autophagosomes to mediate Tom1dependent autophagosome maturation and fusion with the lysosome. Nat Cell Biol. 2012;14:1024-35. https://doi.org/10.1038/ncb2589.

48. Luz S, Cihil KM, Brautigan DL, Amaral MD, Farinha CM, Swiatecka-Urban A. LMTK2-mediated phosphorylation regulates CFTR endocytosis in human airway epithelial cells. J Biol Chem. 2014;289:15080-93. https://doi.org/10. 1074/jbc.M114.563742.

49. Swiatecka-Urban A, Boyd C, Coutermarsh B, Karlson KH, Barnaby R, Aschenbrenner $L$, et al. Myosin VI regulates endocytosis of the cystic fibrosis transmembrane conductance regulator. J Biol Chem. 2004;279:38025-31. https://doi.org/10.1074/jbc.M403141200.

50. Riordan JR. CFTR function and prospects for therapy. Annu Rev Biochem. 2008;77:701-26. https://doi.org/10.1146/annurev.biochem.75. 103004.142532.

51. Conti A, Majorini MT, Fontanella E, Bardelli A, Giacca M, Delia D, et al. Lemur tyrosine kinase 2 (LMTK2) is a determinant of cell sensitivity to apoptosis by regulating the levels of the BCL2 family members. Cancer Lett. 2017;389:5969. https://doi.org/10.1016/j.canlet.2016.12.025.

52. De Vos KJ, Grierson AJ, Ackerley S, Miller CCJ. Role of axonal transport in neurodegenerative diseases. Annu Rev Neurosci. 2008;31:151-73. https://doi. org/10.1146/annurev.neuro.31.061307.090711.

53. Ghavami S, Shojaei S, Yeganeh B, Ande SR, Jangamreddy JR, Mehrpour $M$, et al. Autophagy and apoptosis dysfunction in neurodegenerative disorders. Prog Neurobiol. 2014;112:24-49. https://doi.org/10.1016/j. pneurobio.2013.10.004.

54. Matarin M, Salih DA, Yasvoina M, Cummings DM, Guelfi S, Liu W, et al. A genome-wide gene-expression analysis and database in transgenic mice during development of amyloid or tau pathology. Cell Rep. 2015;10:633-45. https://doi.org/10.1016/j.celrep.2014.12.041.

55. Kusakawa Gl, Saito T, Onuki R, Ishiguro K, Kishimoto T, Hisanaga SI. Calpaindependent proteolytic cleavage of the p35 cyclin-dependent kinase 5 activator to p25. J Biol Chem. 2000;275:17166-72. https://doi.org/10.1074/ jbc.M907757199.

56. Patrick GN, Zukerberg L, Nikolic M, De La Monte S, Dikkes P, Tsai LH. Conversion of p35 to p25 deregulates Cdk5 activity and promotes neurodegeneration. Nature. 1999;402:615-22. https://doi.org/10.1038/45159.

57. Lee MS, Kwon YT, Li M, Peng J, Friedlander RM, Tsai LH. Neurotoxicity induces cleavage of p35 to p25 by calpain. Nature. 2000;405:360-4. https:// doi.org/10.1038/35012636.

58. Nath R, Davis M, Probert AW, Kupina NC, Ren X, Schielke GP, et al. Processing of cdk5 activator p35 to its truncated form (p25) by calpain in acutely injured neuronal cells. Biochem Biophys Res Commun. 2000;274:1621. https://doi.org/10.1006/bbrc.2000.3070.

59. Peterson DW, Ando DM, Taketa DA, Zhou H, Dahlquist FW, Lew J. No difference in kinetics of tau or histone phosphorylation by CDK5/p25 versus CDK5/p35 in vitro. Proc Natl Acad Sci U S A. 2010;107:2884-9. https://doi. org/10.1073/pnas.0912718107.

60. Patrick GN, Zhou P, Kwon YT, Howley PM, Tsai LH. p35, the neuronal-specific activator of cyclin-dependent kinase 5 (Cdk5) is degraded by the ubiquitinproteasome pathway. J Biol Chem. 1998;273:24057-64. https://doi.org/10. 1074/jbc.273.37.24057.

61. Vagnoni A, Perkinton MS, Gray EH, Francis PT, Noble W, Miller CCJ. Calsyntenin-1 mediates axonal transport of the amyloid precursor protein and regulates a $\beta$ production. Hum Mol Genet. 2012;21:2845-54. https://doi. org/10.1093/hmg/dds109.

62. Hirokawa N, Niwa S, Tanaka Y. Molecular motors in neurons: transport mechanisms and roles in brain function, development, and disease. Neuron. 2010;68:610-38. https://doi.org/10.1016/j.neuron.2010.09.039.

63. Saxton WM, Hollenbeck PJ. The axonal transport of mitochondria. J Cell Sci. 2012;125:2095-104. https://doi.org/10.1242/jcs.053850.

64. Cai Q, Pan P-Y, Sheng Z-H. Syntabulin-Kinesin-1 family member 5B-mediated axonal transport contributes to activity-dependent presynaptic assembly. J Neurosci. 2007;27:7284-96. https:/doi.org/10.1523/JNEUROSCI.0731-07.2007.

65. Morfini G. Glycogen synthase kinase 3 phosphorylates kinesin light chains and negatively regulates kinesin-based motility. EMBO J. 2002;21:281-93. https://doi.org/10.1093/emboj/21.3.281.

66. Morfini G, Szebenyi G, Brown H, Pant HC, Pigino G, DeBoer S, et al. A novel CDK5-dependent pathway for regulating GSK3 activity and kinesin-driven motility in neurons. EMBO J. 2004;23:2235-45. https://doi.org/10.1038/sj. emboj.7600237. 
67. Batut J, Howell M, Hill CS. Kinesin-mediated transport of Smad2 is required for signaling in response to TGF- $\beta$ ligands. Dev Cell. 2007;12:261-74. https:// doi.org/10.1016/j.devcel.2007.01.010.

68. Hill CS. Nucleocytoplasmic shuttling of Smad proteins. Cell Res. 2009;19:3646. https://doi.org/10.1038/cr.2008.325.

69. Massagué J, Seoane J, Wotton D. Smad transcription factors. Genes Dev. 2005;19:2783-810. https://doi.org/10.1101/gad.1350705.

70. Katsuno M, Adachi H, Banno H, Suzuki K, Tanaka F, Sobue G. Transforming growth factor- $\beta$ signaling in motor neuron diseases. Curr Mol Med. 2011;11: 48-56. https://doi.org/10.2174/156652411794474356.

71. Town T, Laouar Y, Pittenger C, Mori T, Szekely CA, Tan J, et al. Blocking TGF$\beta-S m a d 2 / 3$ innate immune signaling mitigates Alzheimer-like pathology. Nat Med. 2008;14:681-7. https://doi.org/10.1038/nm1781.

72. Hanger DP, Lau DHW, Phillips EC, Bondulich MK, Guo T, Woodward BW, et al. Intracellular and extracellular roles for tau in neurodegenerative disease. J Alzheimers Dis. 2014;40:S37-45. https://doi.org/10.3233/JAD-132054.

73. Guo T, Noble W, Hanger DP. Roles of tau protein in health and disease. Acta Neuropathol. 2017;133:665-704. https://doi.org/10.1007/s00401-017-1707-9.

74. Pei J-J, Braak E, Braak H, Grundke-lqbal I, lqbal K, Winblad B, et al. Distribution of active glycogen synthase kinase $3 \beta$ (GSK-3 $\beta$ ) in brains staged for Alzheimer disease neurofibrillary changes. J Neuropathol Exp Neurol. 1999;58:1010-9. https://doi.org/10.1097/00005072-199909000-00011.

75. Pei JJ, Grundke-lqbal I, labal K, Bogdanovic N, Winblad B, Cowburn RF. Accumulation of cyclin-dependent kinase 5 (cdk5) in neurons with early stages of Alzheimer's disease neurofibrillary degeneration. Brain Res. 1998; 797:267-77. https://doi.org/10.1016/S0006-8993(98)00296-0.

76. Noble W, Olm V, Takata K, Casey E, Mary O, Meyerson J, et al. Cdk5 is a key factor in tau aggregation and tangle formation in vivo. Neuron. 2003;38: 555-65. https://doi.org/10.1016/S0896-6273(03)00259-9.

77. Flaherty DB, Soria JP, Tomasiewicz HG, Wood JG. Phosphorylation of human tau protein by microtubule-associated kinases: GSK3 $\beta$ and cdk5 are key participants. J Neurosci Res. 2000;62:463-72. https://doi.org/10.1002/10974547(20001 101)62:3<463::AID-JNR16>3.0.CO;2-7.

78. Feng DD, Cai W, Chen X, Bajaj A, Driver J, Schernhammer E, et al. The associations between Parkinson's disease and cancer: the plot thickens. Transl Neurodegener. 2015;4:20. https://doi.org/10.1186/s40035-015-0043-z.

79. Plattner F, Angelo M, Giese KP. The roles of cyclin-dependent kinase 5 and glycogen synthase kinase 3 in tau hyperphosphorylation. J Biol Chem. 2006; 281:25457-65. https://doi.org/10.1074/jbc.M603469200.

80. Wen Y, Planel E, Herman M, Figueroa HY, Wang L, Liu L, et al. Interplay between cyclin-dependent kinase 5 and glycogen synthase kinase 3 beta mediated by neuregulin signaling leads to differential effects on tau phosphorylation and amyloid precursor protein processing. J Neurosci. 2008;28:2624-32. https://doi.org/10.1523/JNEUROSCI.5245-07.2008.

81. LaPointe NE, Morfini G, Pigino G, Gaisina IN, Kozikowski AP, Binder LI, et al. The amino terminus of tau inhibits kinesin-dependent axonal transport: implications for filament toxicity. J Neurosci Res. 2009;87:440-51. https://doi. org/10.1002/jnr.21850.

82. Kanaan NM, Morfini GA, LaPointe NE, Pigino GF, Patterson KR, Song Y, et al. Pathogenic forms of tau inhibit kinesin-dependent axonal transport through a mechanism involving activation of axonal phosphotransferases. J Neurosci. 2011;31:9858-68. https://doi.org/10.1523/JNEUROSCI.0560-11.2011.

83. Kanaan NM, Morfini G, Pigino G, LaPointe NE, Andreadis A, Song Y, et al. Phosphorylation in the amino terminus of tau prevents inhibition of anterograde axonal transport. Neurobiol Aging. 2012;33:826.e15-30. https:// doi.org/10.1016/j.neurobiolaging.2011.06.006.

84. Liu F, Grundke-labal I, labal K, Gong CX. Contributions of protein phosphatases PP1, PP2A, PP2B and PP5 to the regulation of tau phosphorylation. Eur J Neurosci. 2005;22:1942-50. https://doi.org/10.1111/j. 1460-9568.2005.04391.x.

85. Rahman A, Grundke-lqbal I, labal K. Phosphothreonine-212 of alzheimer abnormally hyperphosphorylated tau is a preferred substrate of protein phosphatase-1. Neurochem Res. 2005;30:277-87. https://doi.org/10.1007/ s11064-005-2483-9.

86. Engidawork E, Gulesserian T, Seidl R, Cairns N, Lubec G. Expression of apoptosis related proteins in brains of patients with Alzheimer's disease. Neurosci Lett. 2001;303:79-82.

87. Guo Q, Sopher BL, Furukawa K, Pham DG, Robinson N, Martin GM, et al Alzheimer's presenilin mutation sensitizes neural cells to apoptosis induced by trophic factor withdrawal and amyloid beta-peptide: involvement of calcium and oxyradicals. J Neurosci. 1997;17:4212-22.
88. Balmanno K, Cook SJ. Tumour cell survival signalling by the ERK $1 / 2$ pathway. Cell Death Differ. 2009;16:368-77. https://doi.org/10.1038/cdd. 2008.148.

89. Shaw RJ, Cantley LC. Ras, PI(3)K and mTOR signalling controls tumour cell growth. Nature. 2006;441:424-30. https://doi.org/10.1038/nature04869.

90. Vivanco I, Sawyers CL. The phosphatidylinositol 3-kinase-AKT pathway in human cancer. Nat Rev Cancer. 2002;2:489-501. https://doi.org/10.1038/nrc839.

91. Tran SEF, Holmström TH, Ahonen M, Kähäri VM, Eriksson JE. MAPKJERK overrides the apoptotic signaling from Fas, TNF, and TRAIL receptors. J Biol Chem. 2001;276:16484-90. https://doi.org/10.1074/jbc.M010384200.

92. Frade JM, Ovejero-Benito MC. Neuronal cell cycle: the neuron itself and its circumstances. Cell Cycle. 2015;14:712-20. https://doi.org/10.1080/15384101. 2015.1004937.

93. Ahn KW, Joo Y, Choi Y, Kim M, Lee SH, Cha SH, et al. Swedish amyloid precursor protein mutation increases cell cycle-related proteins in vitro and in vivo. J Neurosci Res. 2008;86:2476-87. https://doi.org/10.1002/jnr.21690.

94. Giovanni A, Wirtz-Brugger F, Keramaris E, Slack R, Park DS. Involvement of cell cycle elements, cyclin-dependent kinases, pRb, and E2F x DP, in Bamyloid-induced neuronal death. J Biol Chem. 1999;274:19011-6.

95. Becker EBE, Bonni A. Cell cycle regulation of neuronal apoptosis in development and disease. Prog Neurobiol. 2004;72:1-25. https://doi.org/10. 1016/j.pneurobio.2003.12.005

96. Liu DX, Greene LA. Neuronal apoptosis at the G1/S cell cycle checkpoint. Cell Tissue Res. 2001;305:217-28. https://doi.org/10.1007/s004410100396.

97. Konishi Y, Lehtinen M, Donovan N, Bonni A. Cdc2 phosphorylation of BAD links the cell cycle to the cell death machinery. Mol Cell. 2002;9:1005-16. https://doi.org/10.1016/S1097-2765(02)00524-5.

98. Park DS, Farinell SE, Greene LA. Inhibitors of cyclin-dependent kinases promote survival of post-mitotic neuronally differentiated PC12 cells and sympathetic neurons. J Biol Chem. 1996;271:8161-9. https://doi.org/10.1074/ jbc.271.14.8161.

99. Copani A, Condorelli F, Caruso A, Vancheri C. Mitotic signaling by $\beta$-amyloid causes neuronal death. FASEB J. 1999;13:2225-34.

100. Park DS, Levine B, Ferrari G, Greene LA. Cyclin dependent kinase inhibitors and dominant negative cyclin dependent kinase 4 and 6 promote survival of NGF-deprived sympathetic neurons. J Neurosci. 1997;17:8975-83.

101. Freeman RS, Estus S, Johnson EM. Analysis of cell cycle-related gene expression in postmitotic neurons: selective induction of cyclin D1 during programmed cell death. Neuron. 1994;12:343-55. https://doi.org/10.1016/ 0896-6273(94)90276-3.

102. Padmanabhan J, Park DS, Greene LA, Shelanski ML. Role of cell cycle regulatory proteins in cerebellar granule neuron apoptosis. J Neurosci. 1999; 19:8747-56

103. Harbour JW, Dean DC. The Rb/E2F pathway: expanding roles and emerging paradigms. Genes Dev. 2000;14:2393-409. https://doi.org/10.1101/gad. 813200.

104. Liu DX, Greene LA. Regulation of neuronal survival and death by E2Fdependent gene repression and derepression. Neuron. 2001;32:425-38. doi: S0896-6273(01)00495-0

105. Harries LW, Perry JR, McCullagh P, Crundwell M. Alterations in LMTK2, MSMB and HNF1B gene expression are associated with the development of prostate cancer. BMC Cancer. 2010;10:315. https://doi.org/10.1186/1471-2407-10-315.

106. Shah K, Bradbury NA. Kinase modulation of androgen receptor signaling: implications for prostate Cancer. Cancer Cell Microenviron. 2015;2:1-8. https://doi.org/10.14800/ccm.1023.

107. Mariani E, Frabetti F, Tarozzi A, Pelleri MC, Pizzetti F, Casadei R. Meta-analysis of Parkinson's disease transcriptome data using TRAM software: whole substantia nigra tissue and single dopamine neuron differential gene expression. PLoS One. 2016;11:e0161567. https://doi.org/10.1371/journal. pone.0161567.

108. Ikiz B, Alvarez MJ, Ré DB, Le Verche V, Politi K, Lotti F, et al. The regulatory machinery of neurodegeneration in in vitro models of amyotrophic lateral sclerosis. Cell Rep. 2015;12:335-45. https://doi.org/ 10.1016/j.celrep.2015.06.019

109. Thomas EA, Coppola G, Tang B, Kuhn A, Kim SH, Geschwind DH, et al. In vivo cell-autonomous transcriptional abnormalities revealed in mice expressing mutant huntingtin in striatal but not cortical neurons. Hum Mol Genet. 2011;20:1049-60. https://doi.org/10.1093/hmg/ddq548.

110. Dey I, Bradbury NA. Activation of TPA-response element present in human Lemur tyrosine kinase 2 ( Imtk2 ) gene increases its expression. Biochem Biophys Reports. 2017;12:140-50. https://doi.org/10.1016/j.bbrep.2017.09.006. 